\title{
Pattern of Ophthalmic Services Utilization in the Asawase Constituency of Ghana.
}

\author{
Mohammed Abdul-Kabir ${ }^{1}$, OnoikhuaEghonghon Ehianata ${ }^{2}$, David Ben Kumah ${ }^{1}$ \\ Eugene Appenteng Osae ${ }^{1}$, Bempong Brifa Benjamin1, Emmanuel Ankamah1, \\ Emmanuel Boateng Baafi ${ }^{1}$, Asare - Bediako Bright ${ }^{1}$ \\ ${ }^{1}$ Department of Optometry and Visual Science, Kwame Nkrumah University of Science and Technology, Private \\ Mail Bag, Kumasi, Ghana. \\ ${ }^{2}$ Department of Optometry, Madonna University, Elele Rivers State, Nigeria.
}

\begin{abstract}
Purpose: Our objective was to determine how ophthalmic services were utilized by the people of the Asawaseconstituency in the Ashanti region of Ghana

Methods: One thousand six hundred and thirty (1630)Asawase citizens were sampledthrough a populationbased, cross-sectional study. Study respondents underwent comprehensive eye examination. An interview session was used to source information on their demographics, socioeconomic status, medical and ocular history and recent eye care visits.

Results: There was $84 \%$ participatory rate; 1369 respondents participated in the study. Out of this number,31 $\%$ had never visited an ophthalmologist or optometrist and the 50\% of them who had ever visitedan eye care clinician hadtheir last eye exams over 4 years ago.The study revealed that youngerparticipants, women and the lesseducated were more likely to have not accessed any form of eye care.Majority (31\%) of the participants had never sought for the services of an ophthalmic specialist.
\end{abstract}

Conclusion: The findings of the study suggest that further investigation into the causes of the pooruse of the available ophthalmic serviceswill help understand and improve eye care situation in this particular population.

Keywords: Eye care, services, optometrist, ophthalmologist, underutilization

\section{Introduction}

Elimination of avoidable blindness has more than a decade existed as one of the major programs of The International Agency for the Prevention of Blindness (IAPB) and the World Health Organization (WHO). These organizations aim to eradicate preventable blindness by the year 2020 through the Vision Global Initiative. Thecore strategies of this initiative namely,specific disease control, human resource development, and infrastructure and appropriate technology development have so far yielded some successes [1].

Eye care services and how they are utilized or accessed by people arecrucial in achieving the goals of "Vision 2020" [2]. Ghana's eye care team is primarily made of ophthalmologist, optometrists and ophthalmic nurses. In some health facilities, general practitioners provide basic form of eye care and frequently refer to ophthalmic specialists when necessary. While much of Ghana's health care services including eye care services are located in and readily accessible in cities and regional capitals, data concerning their utilization andinformation on the uptake of eye care services in such areas are nonexistent.

However, such information if available will assist in designing strategies to improve eye care utilization by those who have underutilized them. Herein was an attempt to study to how eye care services were patronized by the people of Asawase Constituency in the Ashanti Region of Ghana.

\section{Methods}

We conducted across-sectional study in the Asawasesubmetro in which we employed a stratified cluster sampling technique. Participants were interviewed in their homes and also at a local community clinic chosen for eye examination conducted part of this study. Eye examination comprised visual acuity measurements, tonometry, refraction and anterior and posterior eye health assessment. Tools used include the Snellen (distance) visual acuity chart, a Perkin's tonometer, a Slitlamp biomicroscope, Welch Allyn direct ophthalmoscope and streak retinoscope.

Participants' demographic information obtained during the interview age and place of residence. Additional information related to participant's medical and eye history including but not limited to previous eye disease, eye trauma, their previous (recent) eye care visits and their diabetic and hypertensive status. For the purposes of this study, the need for an eye care visit was defined as a presenting Snellen visual acuity of worse $6 / 9$ in the better eye. 
Data analysis was done using Statistical Package for Social Sciences (SPSS) version 17.0. Descriptive statistics was employed. Outcomes were reported as percentages. Continuous values were reported as means \pm standard deviations. $\mathrm{P}<0.05$ was considered significant.

\section{Ethical Consideration}

Approval for our study was granted by the ethical research committee of the Kwame Nkrumah University of Science and Technology in Kumasi, Ghana. We also obtained informed consent from all study participants .The studyadhered to the Declaration of Helsinki.

\section{Results}

A total of 1,369 out of the 1,630 participated in this study; representing a response rate of $84 \%$.The participants were interviewed and examined from December 2011 to January 2012. The mean age of the participants was $43.6 \pm 36.4$ years with an age range of 6-80 years. Out of the total number of respondents, 602 (44\%) were male. Of those who participated, 1260 (92\%) were 20 years of age or older; of which 67\%, $24 \%$, and $9 \%$ were employed, unemployed and retired respectively. About a quarter(24\%)of the participants were illiterate, one out of ten $(10 \%)$ had university education and $6.1 \%$ were still in school.

About 50\% of the 945 participants who had ever utilized eye care services had not had the service in the last four years (Table 1). Participants within the age group $10-19$ registered the highest proportion (83\%) of no visit in the last four years, while those aged 70 years and above registered the least proportion (28\%) of no visit. Two out of five $(40 \%)$ of participants within the age group $50-59$ who had ever had an eye exam had no visit in the last four years. The results revealed the unemployed and women as having higher rates of no visit in the last four years with regards to employment status and gender.

Less educated people were more likely not have accessed ophthalmic services of any form. About 2 out of $10(39 \%)$ of the 151 participants with visual impairment (visual acuity of worse than 6/9 in the better eye) had no history of an eye examination, and among the 92 who had ever been examined, $45 \%$ had not visited eye care facility in the last four years (Table 1).

Table 1: Summary of Participants' Information and Visual Status.

\begin{tabular}{|c|c|c|c|c|c|c|c|c|}
\hline Variable & & & Neve & en examined & Evel & amined & No & last 4 years \\
\hline Sex & No. & $\%$ & No. & $\%$ & No. & $\%$ & No. & $\%$ \\
\hline Males & 602 & 44 & 182 & 30 & 420 & 70 & 194 & 46 \\
\hline Females & 767 & 56 & 242 & 32 & 525 & 69 & 280 & 53 \\
\hline Total & 1369 & 100 & 424 & 31 & 945 & 69 & 474 & 50 \\
\hline Age & No. & $\%$ & No. & $\%$ & No. & $\%$ & No. & $\%$ \\
\hline Under 10 & 41 & 3 & 23 & 56 & 18 & 44 & 13 & 72 \\
\hline $10-19$ & 68 & 5 & 37 & 54 & 31 & 46 & 26 & 83 \\
\hline $20-29$ & 110 & 8 & 45 & 41 & 65 & 59 & 40 & 62 \\
\hline $30-39$ & 246 & 18 & 98 & 40 & 148 & 60 & 80 & 54 \\
\hline $40-49$ & 411 & 30 & 112 & 27 & 299 & 73 & 171 & 57 \\
\hline $50-59$ & 287 & 21 & 70 & 24 & 217 & 76 & 88 & 40 \\
\hline $60-69$ & 137 & 10 & 27 & 20 & 110 & 80 & 40 & 36 \\
\hline $70+$ & 69 & 5 & 12 & 17 & 57 & 83 & 16 & 28 \\
\hline Total & 1369 & 100 & 424 & 31 & 945 & 69 & 474 & 50 \\
\hline Education & No. & $\%$ & No. & $\%$ & No. & $\%$ & No. & $\%$ \\
\hline None & 329 & 24 & 122 & 37 & 207 & 59 & 147 & 71 \\
\hline Primary & 192 & 14 & 66 & 34 & 126 & 63 & 81 & 64 \\
\hline JHS/Middle & 493 & 36 & 167 & 34 & 326 & 58 & 152 & 47 \\
\hline SHS/Secondary & 218 & 16 & 54 & 25 & 164 & 77 & 60 & 37 \\
\hline Tertiary & 137 & 10 & 15 & 11 & 122 & 89 & 34 & 28 \\
\hline Total & 1369 & 100 & 424 & 31 & 945 & 69 & 474 & 50 \\
\hline Employment & No. & $\%$ & No. & $\%$ & No. & $\%$ & No. & $\%$ \\
\hline Employed & 922 & 67 & 271 & 29 & 651 & 71 & 310 & 47 \\
\hline Unemployed & 324 & 24 & 127 & 39 & 197 & 69 & 123 & 62 \\
\hline Retired & 123 & 9 & 26 & 21 & 97 & 83 & 41 & 42 \\
\hline Total & 1369 & 100 & 424 & 31 & 945 & 69 & 474 & 50 \\
\hline Visual Acuity & No. & $\%$ & No. & $\%$ & No. & $\%$ & No. & $\%$ \\
\hline $6 / 9$ or better & 1218 & 89 & 365 & 30 & 853 & 70 & 432 & 51 \\
\hline Worse than $6 / 9$ & 151 & 11 & 59 & 39 & 92 & 61 & 42 & 45 \\
\hline Total & 1369 & 100 & 424 & 31 & 945 & 69 & 474 & 50 \\
\hline
\end{tabular}




\section{Discussion}

A crucial component of heath care system performance assessment is the measurement of its coverage. Accessibility to available health care services coupled with the manner in which existing health care programs and facilities are used by individuals is central to effective healthcare coverage [3]. In this study, participant' self-reported history of ever visiting an eye care setup for their needs was used as a measure of how eye care services were utilized by people in the area under study. The results revealed that nearly one out of three (31\%) of the respondents had never had any eye care service. Some 39\% of the participants with vision impairmenthad never been examined by an eye clinician. Younger age groups, men and the less educated were also found to have increased rate of eye care neglect.

Approximately $11 \%$ of the participants were visually impaired based on their presenting vision. Among the visually impaired nearly two fifth (39\%) had never had any previous eye care visit. With reference to guidelines stated bythe American Academy of Ophthalmology, an ophthalmic examination is relevant at least every five years for non-visually impaired persons aged 30 to 39 years.The same guidelines suggests between one or two eye exams, at least, within a five year period is necessary for persons in sixth decade of life and beyond age [4].The results of this study is far from this guideline as $45 \%$ of the visually impaired group, 54\% for participants in the $30-39$ years age group, $57 \%$ of those in the $40-49$ years age group and $34 \%$ of those aged over 60 years had not seen an eye care clinician visit in the last four years (Table 1), which revealsunderutilization of by majority of our studied population.

Ghana has a relatively good situation. Eye clinics are clustered in the cities and regional capitals with a few sparsely located in remote areas. Trained eye care professionals in these areas include ophthalmologists, optometrists and ophthalmic nurses. These professionals work in both public and private clinics across the country. The National Health Insurance Scheme covers part of the fees in the public hospitals as well as some of the private hospitals. In spite of this relatively good eye care services and systems delivery, there remains a poor understanding of the reasons why ophthalmic services in certain areas are underutilized.

There have been several other studies on underused eye care services, with some highlighting factors and or reasons similar to what we found[2,5,6]. Different rates of ophthalmic services utilization have been reported depending on target population and geographical locations. Whereas Wang and colleagues [7] reported 99\% ophthalmic service utilization in an older Australian population, Nirmalan and colleagues reported $64.5 \%$ eye care visit in a study that targeted rural Indians [5].Other studies targeted age[7,8] and diabetics $[9,10]$ and reported different rates of ophthalmic services utilization.

Other studies found increasing rates of eye care utilization with increasing age $[2,5,7,8,11]$. This is expected because of age related ophthalmic conditions and visual impairments. Age therefore becomes a factor of need that motivates people to seek eye care.

This study showed that a greater number of participants those aged 60 years and above and those who were visually impaired (visual acuity worse than 6/9) had had no form of ophthalmological services in their life.

The relationship revealed in this study with regards to gender and eye care utilization conflict with other studies that showed higher rate of utilization by women $[7,12,13]$ but agrees with what has been reported in other studies [5](where men sought eye care more than women. A study conducted by Clendenin et al., [11] however found no significant difference between genders.

The study further revealed that participants with higher level of education were likely have utilized eye care than the less educated. This finding could be explained in terms of their greater knowledgeability. They perhaps, were also concerned about their health and found it reasonableto seek health care services when appropriate. A plausible reason to this finding may also be the generally high socioeconomic status of the elite; they may thus find eye care services in the area more affordable compared to the least educated and uneducated[2,5,7,8,13].

A major limitation to this study is that, some influential factors to eye care utilization like, access to services, attitude of providers and cost were not assessed. Anderson et al, [14] came out with a behavioral model that put factors affecting ophthalmic care utilization in to three categories: predisposing, enabling, and need [14]. The level of neglect demand in-depth studies to look for other factors.

While we did not look into the specifics of financial constraints, distance of the clinic from participant's homes and challenges with transportation, it suffices to say that these are could all influence are findings. We thus seek to state that, readers should consider our findings in the light of possible challenges to our study design. This study cannot be generalizedsince the samplecomprisingAsawase inhabitants cannot represent the entire region or the country. There is therefore the need for similar studies to be done in other parts of the country. 


\section{Conclusion}

This study revealed that a greater percentage of the total number of participants studiedhad not accessed any ophthalmic care services in their lifetime. This was especially common among the least educated and younger participants.. Conscious effort therefore has to be made to determine the causes of underutilization of the available ophthalmic services in the population.

\section{Conflict of Interest:}

The authors declare that they have no conflicts of interest regarding the publication of this article.

\section{Financial Relationship:}

The authors did not receive funding from any party for the conduct of this study. All costs incurred in the design and conduct of the study was borne by the investigators themselves.

\section{References}

[1] World Health Organization: Vision 2020. Global initiative for the elimination of avoidable blindness. In Fact Sheet No 1213. Geneva: WHO; 2000.

[2] Fotouhi A, Hashemi H, Mohammad K. Eye care utilization patterns in Tehran population: a population based cross-sectional study. BMC ophthalmology. 2006;6(1):1

[3] Shengelia B, Murray CJL, Adams OB: Beyond Access and Utilization: Defining and Measuring Health System Coverage. In Health Systems Performance Assessment: Debates, Methods and Empiricism. Edited by: Murray CJL, Evans DB. Geneva: WHO; 2003:221-234.

[4] American Academy of Ophthalmology: Comprehensive Adult Eye Evaluation. American Academy of Ophthalmology Preferred Practice Patterns Committee; 2000:12.

[5] Nirmalan PK, Katz J, Robin AL, Krishnadas R, Ramakrishnan R, Thulasiraj RD, Tielsch J: Utilization of eye care services in rural south India: the Aravind Comprehensive Eye Survey. Br J Ophthalmol2004 ,88:1237-1241.

[6] Ellwein LB, Friedlin V, McBean AM, Lee PP: Use of eye care services among the 1991 Medicare population. Ophthalmology1996 ,103:1732-1743.

[7] Wang JJ, Mitchell P, Smith W: Use of eye care services by older Australians: the Blue Mountains Eye Study. Aust N Z J Ophthalmol1999, 27:294-300.

[8] Orr P, Barron Y, Schein OD, Rubin GS, West SK: Eye Care Utilization by Older Americans: The SEE Project. Ophthalmology1999 ,106:904-909.

[9] McCarty CA, Lloyd-Smith CW, Lee SE, Livingsto PM, Stanislavsky YL, Taylor HR: Use of eye care services by people with diabetes: the Melbourne Visual Impairment Project. Br J Ophthalmol1998 ,82:410-414.

[10] Moss SE, Klein R, Klein BEK: Factors associated with having eye examinations in persons with diabetes. Arch FamMed1995 4:529-534.

[11] Clendenin C, Coffey M, Marsh M, West S. Eye care utilisation patterns in a rural county in Ireland: implications for service delivery. British journal of ophthalmology. 1997;81(11):972-5.

[12] Keeffe JE, Weih LM, McCarty CA, Taylor HR: Utilization of eye care services by urban and rural Australians. Br J Ophthalmol2002,86:24-27.

[13] Dandona R, Dandona L, Naduvilath TJ, McCarty CA, Rao GN: Utilization of eye care services in an urban population in southern India: the Andhra Pradesh eye disease study. Br J Ophthalmol2000 ,84:22-27.

[14] Andersen RM: Revisiting the behavioral model and access to medical care: does it matter? J Health SocBehav1995 ,36:1-10. 